\title{
Particle emissions of a railway line determined by detailed single particle analysis
}

\author{
R. Lorenzo ${ }^{a, b}$, R. Kaegia, R. Gehrig ${ }^{a}$, B. Grobéty ${ }^{b}$ \\ aLaboratory for Air Pollution \& Environmental Technology, Empa, Materials Science \& Technology, Ueberlandstr. 129, \\ $\mathrm{CH}-8600$ Duebendorf, Switzerland \\ bInstitute for Mineralogy and Petrography, University of Fribourg, Ch. du Musée 6, \\ $\mathrm{CH}-1700$ Fribourg, Switzerland
}

\begin{abstract}
The goal of this study was to identify and quantify particles emitted from railway traffic. For that purpose PM10 samples were collected near a busy railway line using a wind direction and speed controlled sampling equipment consisting of five devices. Measurements taken perpendicular to the railway lines at $10 \mathrm{~m}, 36 \mathrm{~m}$ and $120 \mathrm{~m}$ distance enable an identification and separation of particles caused by the railway traffic from background particles. Morphology and chemistry of more than 11'000 particles were analyzed by computer controlled scanning electron microscopy (CCSEM). Based on chemical composition five particle classes are defined and assigned to their sources. The mass of the individual particles is determined by multiplying their volumes, calculated based on their morphology with a density assigned specifically to each particle class. The density of the particle classes is derived from their chemical composition. To estimate the PM1O contributions of the railway lines, the mass of PM1O at $120 \mathrm{~m}$ (background, not influenced by the railway lines) is subtracted from the mass of PM10 at $10 \mathrm{~m}$. The emissions of the railway lines are dominated by 'iron' particles, which contribute $2.9 \mathrm{\mu g} \mathrm{m}^{-3}$ or $67 \%$ to the railway related PM10. In addition, 'aluminium' and 'calcium' particles contribute also to the railway related PM10 $\left(1.0 \mu \mathrm{g} \mathrm{m}^{3}\right.$ or $23 \%$ for the 'aluminium' and $0.4 \mathrm{\mu g} \mathrm{m}^{-3}$ or $10 \%$ for the 'calcium' particles). These particles are assigned to abrasion of the gravel bed and re-suspension of mineral dust.

Long-term gravimetric results of the contribution of iron to the mass of railway related PM10 from a study performed earlier at the same site are in good agreement with the data presented in this study.
\end{abstract}

Keywords: SEM/EDX; Particle analysis; Morphology; Railway; PM10

\section{Introduction}

Adverse health effects of airborne particulate matter are reviewed in numerous studies (Harrison and Yin 2000; Oberdorster 1995a; Oberdorster et al. 1995b; Pope 2000). Anthropogenic emissions of particulate matter largely result from industry, heating installations and traffic. A considerable fraction of the total human exposure to particulate matter results from traffic. The contribution of road traffic has been investigated in detail in the BAB II project (Rosenbohm et al. 2005).

Particulate emissions of railway traffic have only been addressed in a few studies which focus on subway systems. Adams et al. (2001) used gravimetric high flow personal samplers to study the PM2.5 personal exposure level during journeys in the subway system of London. A similar study in the Stockholm underground was performed by Johansson and Johansson (2003). They used a tapered element oscillating microbalance (TEOM) to measure the PM10 and PM2.5 concentrations on the platform. The personal exposure to airborne metals and total suspended particulate matter of commuters in the London underground was the subject of a study by Pfeifer et al. (1999). In addition to gravimetric methods they used inductively coupled plasma-mass spectroscopy (ICP-MS) to get information on the chemical composition of the bulk aerosol. The same methods were used by Chillrud et al. (2004) to investigate the exposure of teenagers to $\mathrm{Mn}, \mathrm{Cr}$ and $\mathrm{Fe}$ in the New York subway.
In addition to gravimetry Aarnio et al. (2005) monitored the particle number concentrations with a differential mobility particle sizer (DMPS) and determined the elemental composition of the PM2.5 in the Helsinki subway system using energy dispersive $\mathrm{X}$-ray fluorescence (EDXRF). However, no information on the level of the individual particles has been collected. Birenzvige et al. (2003) used a single particle fluorescence analyser to count, size and distinguish between bio aerosols and other aerosols. In addition, a limited number of selected single particles were manually analyzed with a scanning electron microscope.

The use of single particle analysis to obtain more detailed information about size, morphology and chemical composition on the level of the individual particle has been documented in many papers (Katrinak et al. 1995; Paoletti et al. 1999; Sitzmann et al. 1999; VanBorm and Adams 1988; VanMalderen et al. 1996a, b; Xhoffer et al. 1991).

In this study single particle analysis was used to quantify the contribution of railway traffic to ambient PM10 concentrations. Based on a detailed single particle analysis of samples collected at different distances from the railway lines, an emission profile of the railway was derived. The railway induced PM10 concentrations were obtained by calculating the individual particle volumes (based on their morphological parameters) and multiplying them with a density derived from the analyzed chemical composition. The obtained PM10 concentrations are compared to gravimetrically determined PM10 concentrations from another study performed at the same sampling site. 


\section{Experimental}

\subsection{Sampling site}

The sampling campaign was conducted at Juchhof near Zurich (Switzerland), a sport centre with several football grounds next to a busy railway line with more than 700 trains per day, all electricity powered. No other major particle source (e.g. power plants, heavy industry) can be found nearby. Since the campaign took place during December 2004 and the training fields were closed for winter, no activities and hardly any local road traffic disturbed the measurements. The closest busy roads are about $200 \mathrm{~m}$ to the south and about $250 \mathrm{~m}$ to the north, respectively; the bridge crossing the railway lines is frequented only by very few vehicles (Figure 2.1). Due to snowfall the week before the campaign, gravel from traction sanding was still present on public roads. However, the snow melted completely before the measurements and conditions were dry for the duration of the campaign.

Five PM10 sampling devices were deployed according to the layout given in Figure 2.1. To distinguish particle emissions of the railway from background, three sampling devices were positioned at $10 \mathrm{~m}, 36 \mathrm{~m}$ and $120 \mathrm{~m}$ from the railway lines. To estimate the reproducibility of the measurements two additional devices were placed at $10 \mathrm{~m}$ from the tracks $50 \mathrm{~m}$ to either side of the three devices just mentioned.

The five sampling devices were operated simultaneously and switched on and off by a wind direction and speed sensor (see Figure 2.1 and Table 2.1 for details) in order to ensure that the sampling only occurred with wind directions from railway influenced sectors. The wind parameters were measured at the central $10 \mathrm{~m}$ position, $4 \mathrm{~m}$ above ground level.

\subsection{Sampling and analysis}

To investigate single particles by electron microscopy it is essential to limit the sampling time and hence the filter load in a way to get well separated particles on the filter and to avoid multiple particle deposition on the same filter spot. Further, it is critical to have a homogeneous distribution of particles on the filter. This enables a quantification of the results which are based on the analysis of a small fraction of the filter area only.

We performed several experiments to check the homogeneity of the particle distribution on the filters of our PM10 samplers and to optimise the sampling time (filter load). Several areas $\left(0.08 \mathrm{~mm}^{2}\right.$ each) of a filter were analyzed using computer controlled scanning electron microscopy (CCSEM). The relative standard deviation of the particle number on the filter between the different fields was

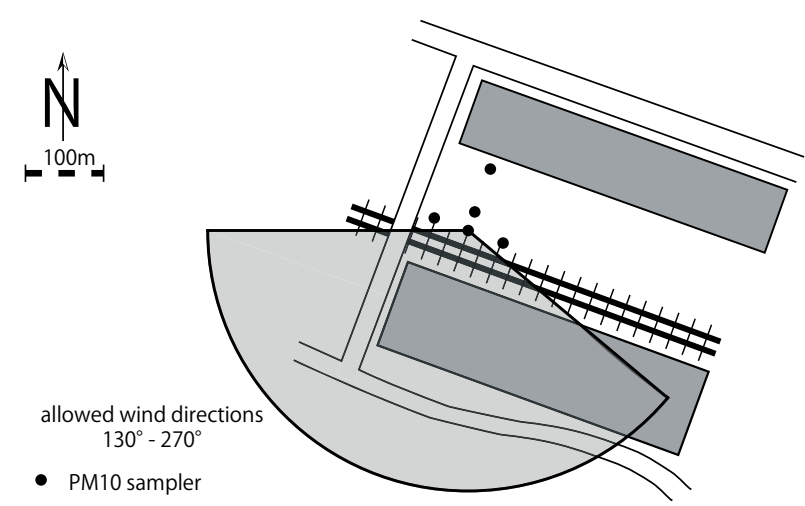

Fig. 2.1. Schematic representation of the sampling area.

about $10 \%$ and no size fractionation could be observed. The final parameters used for the measurements near the railway lines are derived from these results and are listed in Table 2.1.

Particles were sampled on Nuclepore filters $(0.4 \mu \mathrm{m}$ pore diameter). Five areas on each filter were analyzed. For that purpose, five concentric rings with equal areas were defined on each filter and one rectangular area out of every ring was selected and analyzed. In total an area of $0.4 \mathrm{~mm}^{2}$ was investigated on each filter. The filters were analyzed with an environmental scanning electron microscope (ESEM, FEI XL 30 FEG) without any further treatment. Elemental analysis was performed with an energy dispersive X-ray spectrometer (EDX, EDAX), attached to the microscope. The experimental parameters for the analysis are given in Table 2.2.

Particles were detected based on their backscattered electron signal and individually analyzed using the EDX signal. Images and analytical data of all particles were stored automatically.

For further analysis a minimum particle diameter of $0.5 \mu \mathrm{m}$ (projected area equivalent diameter) was chosen. Smaller particles were discarded as the resulting EDX signal was often too weak. To determine the detection limits of the elements of interest and to verify the spectra of specific particles, all EDX spectra were manually reviewed. In total approximately 11'000 particles were analyzed and of these more than 90\% could be classified using our classification scheme (Figure 2.2). The main reason for non-classified particles was mechanical and/or electronic shifts of the sample or beam during data acquisition. Therefore, the corresponding EDX spectra resulted from the filter rather than from the particle. A small portion of particles $(\sim 1 \%)$ consisted of elements not considered by our classification algorithm, such as $\mathrm{Ti}$ or $\mathrm{Cu}$.

Table 2.1

Table of parameters used for the final sampling run.

\begin{tabular}{|c|c|c|c|}
\hline \multicolumn{4}{|c|}{ Sampling Parameter } \\
\hline Filter & & Setup & \\
\hline Type & Nuclepore ${ }^{\circledR}$ & Number of Samplers used & 5 \\
\hline Pore Diameter & $0.4 \mu \mathrm{m}$ & Flow & $41 \min ^{-1}$ \\
\hline \multirow{4}{*}{ Filter Diameter } & $2.5 \mathrm{~cm}$ & Sampling Period & 6.-10. December 2004 \\
\hline & & Sampling Time (wind conditions within specified ranges) & $4 \mathrm{~h}$ \\
\hline & & Range of Wind Speeds & $0.4-10 \mathrm{~m} \mathrm{~s}^{-1}$ \\
\hline & & Range of Wind Directions & $130-270^{\circ}$ \\
\hline
\end{tabular}




\section{Results and discussion}

\subsection{Classification of the particles}

The net intensities of the EDX spectra were used as a basis for the classification of the particles. The flow chart given in Figure 2.2 describes the algorithm used to distinguish five particle classes. Since particles were sampled on polycarbonate filters, the O-peak was not used for particle classification. The classification scheme is based on mineralogical criteria. Geological particles are essentially silicates (feldspars, quartz and clays) with minor amounts of carbonates (calcite) and sulphates (gypsum). The chemistry of these particles can be unambiguously distinguished from Fe particles (metals, oxides), which are caused by the local railway lines. Thus, the classification criteria as shown in Figure 2.2 are unequivocal.

$$
I_{P}>3 \sqrt{\frac{I_{B}}{t}}+I_{B}
$$

To calculate the detection limits for the individual elements the three-sigma criterion (1) was applied, where $I_{P}$ is the intensity of the peak (counts per second), $I_{B}$ the background intensity and $t$ the acquisition time. In the following paragraphs, the different classes will be briefly described.

\subsection{1 'Iron' class}

Particles of this class consist almost entirely of iron. Occasionally, minor amounts of other elements were detected caused by smaller particles sitting on top of - or close to - the iron particles.

Most of the iron particles are spherical in shape and some of them were cracked and appeared to be hollow. The morphology indicates that these particles were generated by a high temperature process. Other particles looked like splinters and were most likely generated by mechanical abrasion.

\subsection{2 'Aluminium' class}

The particles of the 'aluminium' class consist mostly of aluminium and silica and were assigned to feldspars. This is, of course, a simplification due to the fact that our classification scheme does not distinguish between feldspars and clay minerals. However, the error in the calculated mass of the particles resulting from this simplification is rather small, as the densities of these minerals are similar.

Among the particles of the 'aluminium' class two different shapes were observed. About half of the particles appear as fragments and are probably the result of mechanical abrasion. The other half of the particles are spherical in shape, which indicates that they were generated by a high temperature process.

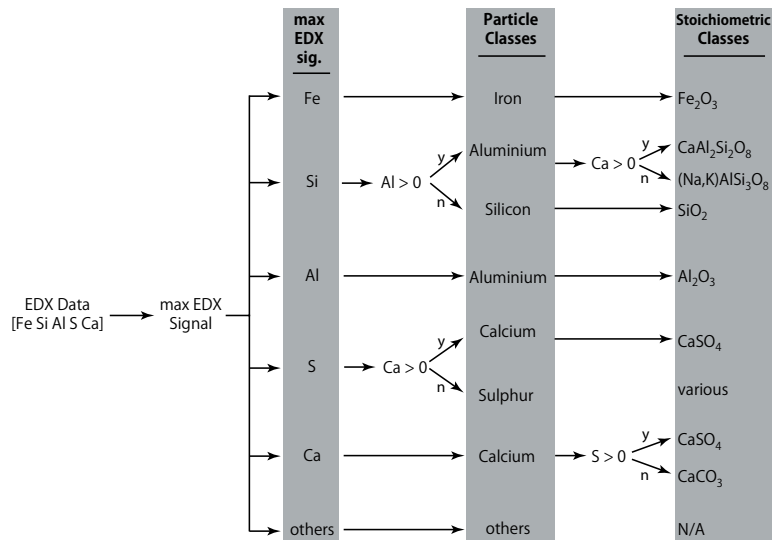

Fig. 2.2. Algorithm for particle classification.

Feldspar was found as component of the gravel underneath the railway tracks. During breaking enough heat is produced to melt iron particles. This temperature is also high enough to melt feldspar particles, which could explain the spherical shapes.

\subsection{3 'Silicon' class}

Most of the particles of the 'silicon' class ( 99\%) consist entirely of silicon and could therefore be identified as quartz. Particles of the 'silicon' class were dominantly fragments with sharp edges, a typical morphology of fractured quartz. Quartz was also found as component of the gravel underneath the railway tracks.

\subsection{4 'Calcium' class}

The 'calcium' class consists of particles dominated by calcium. In addition, sulphur dominated particles with calcium above the detection limit were also assigned to the 'calcium' class.

Particles of the 'calcium' class were angular fragments with a variety of shapes. Sharp edges indicate that these particles are abrasion products. Carbonate rocks were also found in the gravel beneath the railway tracks.

\subsection{5 'Sulphur' class}

For particles of the 'sulphur' class, sulphur had to be the strongest EDX signal and calcium had to be below the detection limit.

Images taken at higher magnifications revealed that 'sulphur' class particles are mostly chains and fractallike structures consisting of spheres smaller than 40nm in diameter, commonly described as soot (Buseck et al. 2000; Chen et al. 2005; Li et al. 2003a; Li et al. 2003b; Posfai et al. 2003). These particles are most likely sulphur coated soot particles and were thus assigned to vehicular exhausts.

Table 2.2

Table of parameters used for the analysis of the five filters.

\begin{tabular}{|c|c|c|c|c|c|}
\hline \multicolumn{6}{|l|}{ ESEM / EDX Parameters } \\
\hline ESEM & & & EDX & & \\
\hline High Tension & 15 & $\mathrm{kV}$ & Image Resolution & $512 \times 400$ & $\mathrm{px}$ \\
\hline Pressure & 0.9 & torr & Particle Sizes & $0.5-15$ & $\mu \mathrm{m}$ \\
\hline Spot Size & 3 & & Acquisition Time & 15 & s (live) \\
\hline Magnification & 4 & $\mathrm{kx}$ & Particles Analyzed & $>11^{\prime} 000$ & (all filters) \\
\hline Area Analyzed (per filter) & 0.4 & $\mathrm{~mm}^{2}$ & & & \\
\hline
\end{tabular}


Alternatively particles of this class appeared as smooth, irregularly shaped particles which might be fragments of biological particles.

\subsection{6 'Other' particles}

A small fraction of the analyzed particles $(<10 \%)$ could not be classified based on our algorithm. This can be caused by one of the following reasons: The particle shifted during the image acquisition, the software combined two touching particles or the particle consisted entirely of elements not considered in our classification, such as $\mathrm{Ti}$ or $\mathrm{Cu}$.

A manual review of the recorded EDX spectra showed that the majority of the not classified particles shifted during image acquisition and, thus, can be attributed to software errors. The remainder of the particles not classified consisted of elements not considered in our analysis.

\subsection{Profiles perpendicular to the railway line}

Figure 2.3 shows the change in particle number for each particle class with increasing distance from the railway lines. The average of the three measurements at $10 \mathrm{~m}$ distance is used for the $10 \mathrm{~m}$ site in Figure 2.3. The standard deviations were calculated from these three simultaneous measurements and are given as two sigma error bars. As the sampling and analysis method was identical, the same relative standard deviation has also been used to estimate the two sigma error margins for the measurements at $36 \mathrm{~m}$ and $120 \mathrm{~m}$ distance.

All particle types, except the 'silicon' class, show decreasing number concentrations with increasing distance from the railway. The decrease is in good agreement with the expected changes described by Sharan et al. (1996) who developed a mathematical model for atmospheric dispersion in low wind conditions.

The numbers of the 'iron' class particles drop much faster between $10 \mathrm{~m}$ and $36 \mathrm{~m}$ than between $36 \mathrm{~m}$ and $120 \mathrm{~m}$ which shows that the railway traffic is a strong source of particles of the 'iron' class. However, it also indicates that the background concentration for 'iron' particles is not yet reached at $120 \mathrm{~m}$.

The number of 'aluminium' class particles (dashed line) decreases significantly between the $10 \mathrm{~m}$ and the $36 \mathrm{~m}$ site but stays constant afterwards. This indicates that the railway lines are a source for 'aluminium' class particles. However, at $36 \mathrm{~m}$ the particle numbers already reached the background level for 'aluminium' particles, indicating only a moderate contribution from the railway traffic to the 'aluminium' class particle number concentration of PM10 in general.

The evolution of the 'calcium' class particle concentration (dash-dotted line) is similar to that of the 'aluminium' class particles. After a strong decrease in particle numbers from $10 \mathrm{~m}$ to $36 \mathrm{~m}$, the curve gets considerably flatter

Table 2.3

Densities used for the calculation of the mass contributions of the particle classes.

\begin{tabular}{lr}
\hline Densities (Particle Classes) & \\
\hline Class & Density $\left[\mathrm{g} \mathrm{cm}^{-3}\right]$ \\
\hline Iron & \\
Aluminium & 5.5 \\
Silicon & 2.6 \\
Calcium & 2.7 \\
Sulphur & 2.35 \\
\hline
\end{tabular}

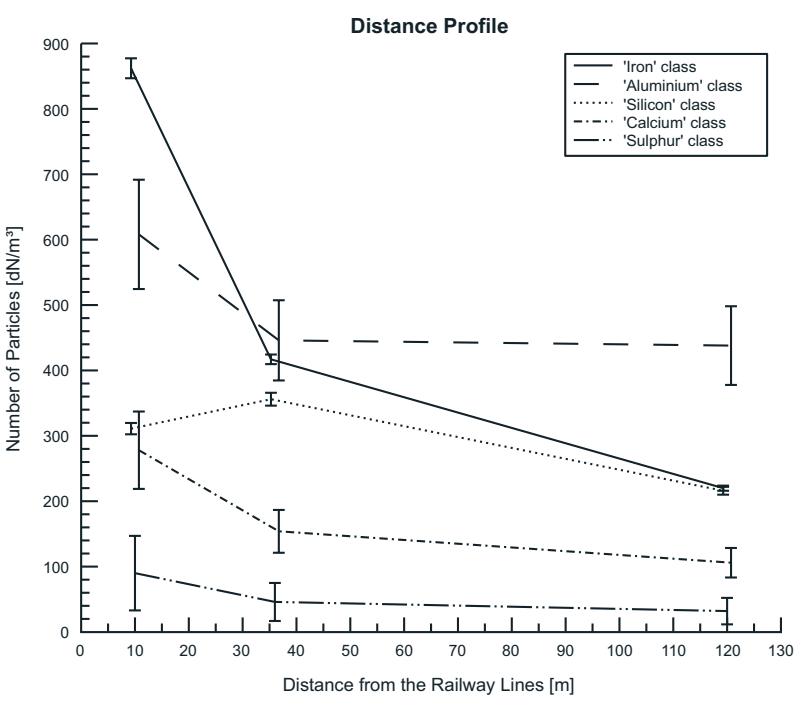

Fig. 2.3. Distance profile for the five particle classes. The error bars (two sigma) are calculated from the standard deviation of the three sampling sites at $10 \mathrm{~m}$ distance from the railway lines. The values at $10 \mathrm{~m}$ are average values from the three sampling sites at that distance. For better readability of the figure some plots are slightly shifted horizontally to prevent overlapping of data points and error bars.

from $36 \mathrm{~m}$ to $120 \mathrm{~m}$. Thus, railway traffic is also a source for particles of the 'calcium' class.

A different behaviour can be observed for the change in particle number of 'silicon' particles (quartz) (dotted line) with increasing distance to the railway lines. The highest particle number is observed at $36 \mathrm{~m}$ and declines towards both sides (10 m and $120 \mathrm{~m}$ ). This indicates an additional source located between the $10 \mathrm{~m}$ and the $36 \mathrm{~m}$ sampling site. Because the number concentrations of quartz particles are higher at $10 \mathrm{~m}$ than at $120 \mathrm{~m}$ and the sampling devices were only operated while the wind was blowing from the railway lines, it can be concluded that the railway's gravel bed, which contains granitoid rocks, is a source for the 'silicon' class particles. A second source is most likely a heap of quartz sand located at about $20 \mathrm{~m}$ distance from the railway lines, between the $10 \mathrm{~m}$ and $36 \mathrm{~m}$ sampling site. This sand is used on the nearby football grounds to reduce the formation of water pools after heavy rainfalls.

The number concentration of 'sulphur' particles (dashed double dotted line) does not change with increasing distance from the railway lines. This indicates that the measured 'sulphur' particles are not related to the railway traffic but rather represent a background concentration. This agrees well with our previous assignment of the 'sulphur' class particles to combustion sources based on morphological criteria. It should be noted that the trains at the investigated site were exclusively electricity powered.

\subsection{Mass calculations}

The total mass of each particle class was calculated based on the individual particle morphology and the density of the respective classes which corresponded to the densities of the minerals listed in Table 2.3. The projected area of the particles is calculated by pixel counting $\left(A_{i}\left[\mu \mathrm{m}^{2}\right], i\right.$ being the particle identification index). A second parameter which is directly derived from the particle image is the length of the longest particle axis $\left(L_{i}[\mu \mathrm{m}]\right)$ (see Figure 2.4 for details). Both parameters are determined by the particle analysis software. 

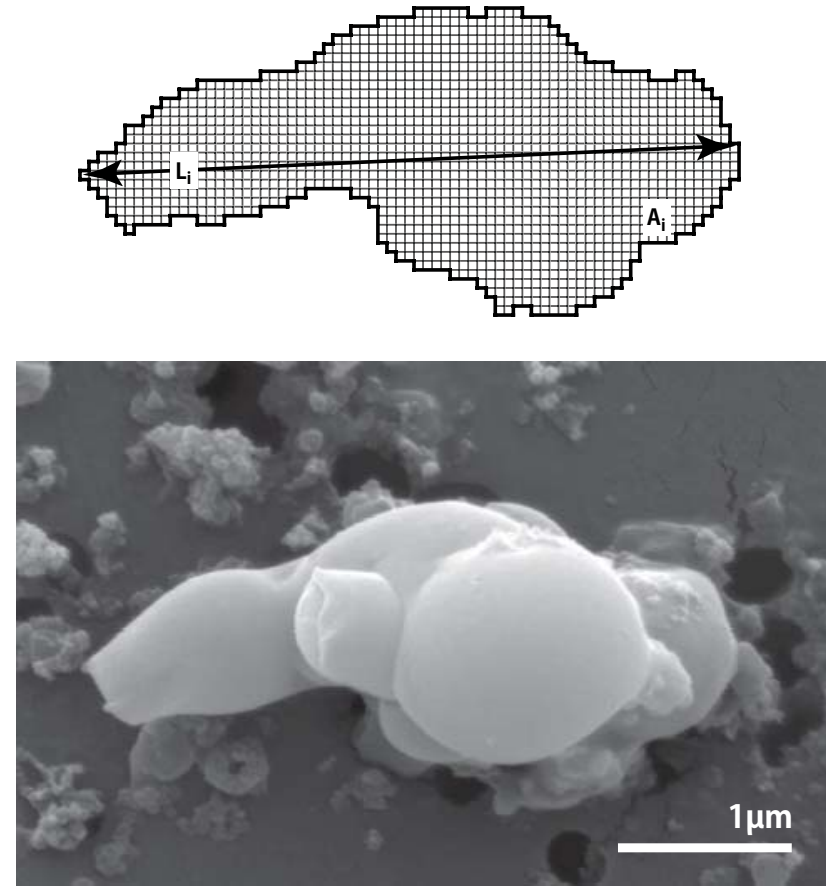

Fig. 2.4. Illustration of morphological parameters of the particles as determined by the particle software. $A_{i}$ : optical projected area (determined by pixel count); $L_{i}$ l longest particle axis (determined by pixel count).

Since most particles are not spherical, their volumes were approximated by prolate ellipsoids $\left(V_{E, i}\right)$, according to (2).

$$
V_{E, i}=\frac{4}{3} A_{i}^{2} \frac{2}{L_{i} \pi}
$$

Calculations were, therefore, based on directly measured parameters. It can be assumed that the particles will lie on their largest side rather than on the tip. Thus, cigars - prolate ellipsoids - are better approximations for cylindrical or cube like objects than spheres or oblate ellipsoids.

To determine the contribution of each class to the mass of PM10 $\left(d M_{\text {class }}\right)$ equation 3 was applied with $i$ spanning over all particles present in a specific class, $\rho_{\text {class }}$ being the density for each class as listed in Table 2.3 and $d V_{\text {air }}$ the total volume of air sampled.

$$
d M_{\text {class }}=\frac{\sum_{i} V_{E, i} \rho_{\text {class }}}{d V_{\text {air }}}
$$

In addition to the total mass of the particle classes, size resolved mass plots for each class were calculated. The volume of the prolate ellipsoid $\left(V_{E, i}\right)$ was used to calculate equivalent spherical volume diameters $\left(D_{i}\right)$ according to (4) and the equivalent aerodynamic diameters of the particles $\left(D_{\text {i,air }}\right)$ according to (5) (Baron and Willeke 2001).

$$
\begin{aligned}
D_{i} & =\sqrt[3]{\frac{6 V_{E, i}}{\pi}} \\
D_{i, \text { air }} & =D_{i} \sqrt{\rho_{\text {class }}}
\end{aligned}
$$

This results in size resolved mass distributions of the different particle classes. Particle classes were arranged in 32 size bins - based on $D_{i}$ - covering the range from $0.5 \mu \mathrm{m}$ to $10.1 \mu \mathrm{m}$, the bin size being $0.3 \mu \mathrm{m}$. The resulting particle size distributions were then fitted with exponential functions $\left(f_{\text {class }}\right.$, the $\mathrm{R}^{2}$ values for the fits are all better than 0.9. The fits were used for illustration only; mass calculations were performed with the measured values).

\subsection{Estimation of the railway contribution to local PM1O concentrations}

Figure 2.5 shows the particle mass distribution at $10 \mathrm{~m}$ distance from the railway lines, calculated according to the method described above. Since 'sulphur' particles are not related to the railway lines, this class has been omitted in Fig. 2.5 and will not be considered in the further discussion.

The plots for the 'iron', 'aluminium' and 'calcium' class have their maximum between $2.5 \mu \mathrm{m}$ and $4 \mu \mathrm{m}$ (equivalent aerodynamic diameter) and contribute therefore mostly to the coarse mode. The 'silicon' class contributes almost exclusively to PM2.5, 80\% of the quartz particles are smaller than $1.6 \mu \mathrm{m}$ equivalent aerodynamic diameter.

To quantify the influence of the railway line on the local concentrations, it was assumed that the sampling site at $120 \mathrm{~m}$ distance represents the background concentration (meaning not influenced by the railway lines). This is supported by the fact that the particle number concentration at $120 \mathrm{~m}$ is only slightly smaller than at $36 \mathrm{~m}$ for all particle classes, except for the 'iron' class (see Figure 2.3). The concentration of 'iron' particles continues to decrease between the $36 \mathrm{~m}$ and the $120 \mathrm{~m}$ site, which indicates that background concentrations are probably not reached, yet, and, thus, our calculated mass contribution represents a lower limit for the emission of 'iron' particles. Figure 2.6 shows the difference of the mass distribution between $10 \mathrm{~m}$ and $120 \mathrm{~m}$. The data points for quartz particles between $2.5 \mu \mathrm{m}$ and $6.5 \mu \mathrm{m}$ equivalent aerodynamic diameter are negative and therefore not shown on the plot.

As discussed before, there is a heap of quartz sand serving as a second source for quartz particles between $10 \mathrm{~m}$

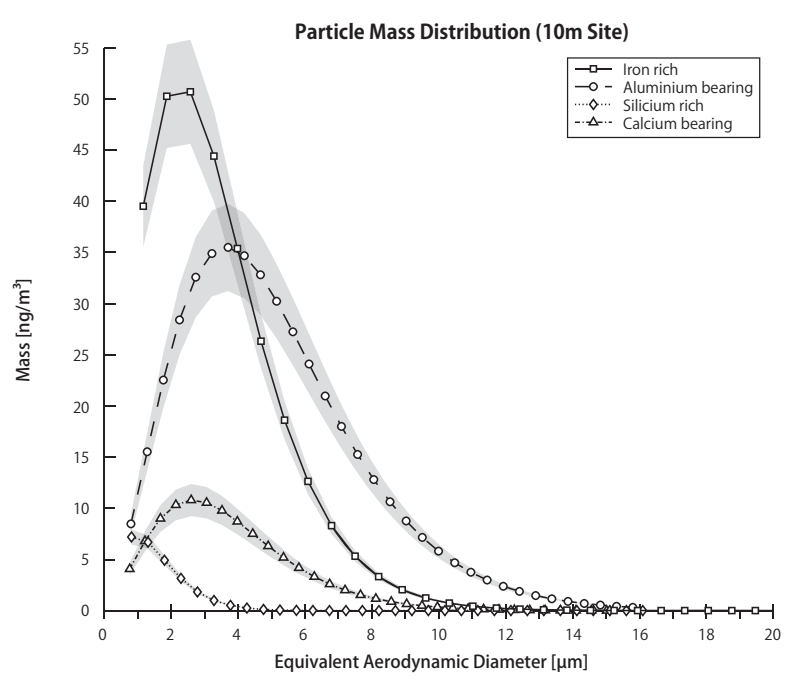

Fig. 2.5. Size resolved mass contributions of the particle classes for the sampling sites at $10 \mathrm{~m}$ distance from the railway lines. The error margins are represented by the grey areas. 


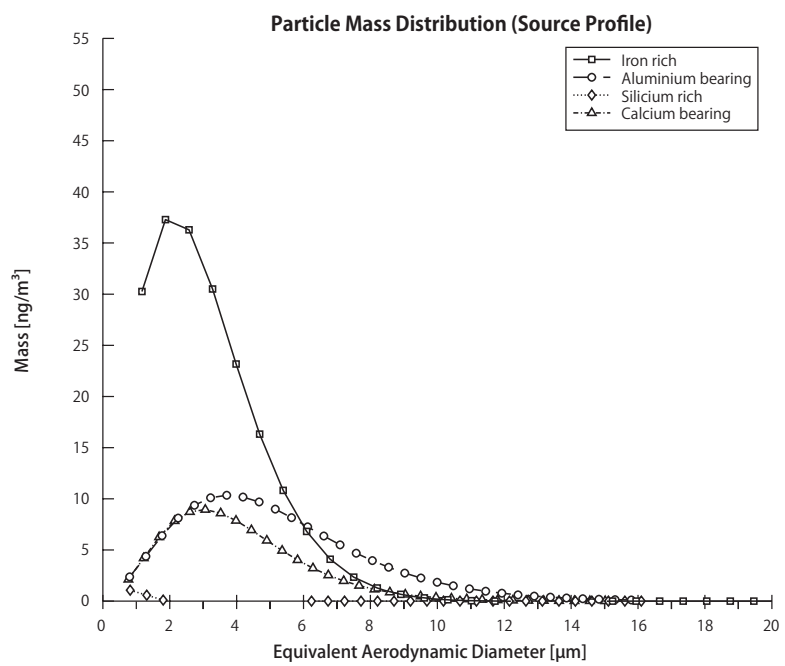

Fig. 2.6. Size resolved mass contribution of the particle classes resulting from the emissions of the railway lines at the $10 \mathrm{~m}$ site (difference between $10 \mathrm{~m}$ and $120 \mathrm{~m}$ sampling site).

and $36 \mathrm{~m}$ from the railway lines. The size distribution of particles resulting from this second source (quartz sand) is shifted towards coarser particles compared to the size distribution observed at $10 \mathrm{~m}$ distance, which explains the negative values. However, as can be seen on Figure 2.5, the contribution of quartz particles to the total PM10 (railway related) is only of minor importance.

In Table 2.4 the mass and number concentrations of the major particle classes at the $10 \mathrm{~m}$ site and the $120 \mathrm{~m}$ site (assumed background) are given. The dominating particle class at $10 \mathrm{~m}$ is the 'iron' class with $3.9 \mathrm{\mu g} \mathrm{m}^{-3}$ followed

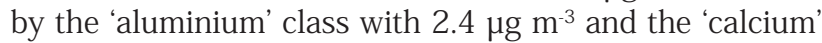
class with $0.6 \mu \mathrm{g} \mathrm{m}^{-3}$. The source strength of the railway lines was calculated as the difference between the $10 \mathrm{~m}$ and the $120 \mathrm{~m}$ site. 'Iron' particles dominated the contribution to the additional PM10 near railway lines $\left(2.9 \mu \mathrm{g} \mathrm{m}^{-3}\right)$. Due to the high background concentration of 'aluminium' particles $\left(1.5 \mu \mathrm{g} \mathrm{m}^{-3}\right)$ the contribution of the railway traffic to this class was only $1 \mu \mathrm{g} \mathrm{m}^{-3}$. There was light snowfall the week before the campaign and temperatures were often below freezing. The rather high background for 'aluminium' particles may therefore be explained by additional emissions caused by traction sanding on public roads, which leads to increased pavement wear (Kupiainen et al. 2005). The source strength for 'calcium' particles was $0.4 \mu_{\mathrm{g} \mathrm{m}}^{-3}$.
Gehrig et al. (2007) performed an extended study between August 2003 and August 2004 at the same sampling site, using gravimetric methods and bulk chemical analysis with the goal to quantify long term average contributions of the railway to local PM10 concentrations. Since they sampled continuously at all wind conditions and the sampling sites were exposed to winds from the railway sector only at about $50 \%$ of the time, their results are not directly comparable to those of our study. However, general trends should still be comparable.

As a reference for background concentrations of PM10 Gehrig et al. (2007) used an urban background site in downtown Zurich, well separated from the railway lines. Based on the chemical analysis of the gravimetric samples at the $10 \mathrm{~m}$ site at Juchhof and the background station, they estimated the railway lines' contribution of iron (calculated as elemental Fe) to local PM10 to be in the order of $1.0 \mathrm{~g} \mathrm{~m}^{-3}$. According to this study, the mass of elemental iron in PM10 generated by railway traffic is $2.0 \mu \mathrm{g} \mathrm{m}^{-3}$ (calculated as the difference between the $10 \mathrm{~m}$ and the $120 \mathrm{~m}$ sampling site at Juchhof). By applying the background concentration of elemental iron as determined by Gehrig et al. to our values of the $10 \mathrm{~m}$ site, the mass of elemental iron in PM10 generated by railway traffic totals in $2.1 \mu \mathrm{g} \mathrm{m}^{-3}$. Therefore, the error caused by our assumption that the $120 \mathrm{~m}$ sampling site represents the local background for PM10, is in the order of $10 \%$. Considering that we measured exclusively during a period of direct wind influence from the railway, results from both studies are in excellent agreement.

\section{Conclusions}

In this study the method of detailed single particle analysis was used to characterize particulate emissions from a railway line. Five particle classes - 'iron', 'aluminium', 'silicon', 'calcium' and 'sulphur' - were distinguished. The 'iron' class particles were appointed to the wear of tracks, as well as wheels and breaks of the trains. Most of the 'aluminium' class particles are of geological origin (feldspar or clay minerals). The gravel bed of the railway lines is most likely the source for the elevated number concentration of 'aluminium' class particles close to the railway lines. Two different sources contribute to the 'silicon' - quartz - particles. The gravel bed of the railway lines and a heap of quartz sand located between the $10 \mathrm{~m}$ and 36 m sampling site. The 'calcium' class particles consisted mostly of calcium sulphate originating from re-suspension

Table 2.4

Calculated mass contributions of the three railway related particle classes. Particles were approximated as prolate ellipsoids with the long axis being $L_{i}$ and projected area $A_{i}$ (see Fig. 4 for details).

\begin{tabular}{|c|c|c|c|c|c|c|}
\hline \multicolumn{7}{|c|}{ Calculated Weight (by Particle Class) } \\
\hline \multirow[b]{2}{*}{ Class } & \multirow[b]{2}{*}{ Minerals } & \multicolumn{2}{|c|}{$10 \mathrm{~m}$ (Average) } & \multicolumn{2}{|c|}{ 120m (Background) } & \multirow{2}{*}{$\begin{array}{l}\text { Source strength } \\
\text { Mass [ng m }{ }^{-3} \text { ] }\end{array}$} \\
\hline & & Particles [\#] & Mass $\left[\mathrm{ng} \mathrm{m}^{-3}\right.$ ] & Particles [\#] & Mass [ng m ${ }^{-3}$ ] & \\
\hline Iron & $\mathrm{Fe}_{2} \mathrm{O}_{3}$ & 862 & 3858.7 & 220 & 950.9 & 2907.8 \\
\hline \multirow{4}{*}{ Aluminium } & Total & 608 & 2442.9 & 438 & 1455.7 & 987.2 \\
\hline & $(\mathrm{Na}, \mathrm{K}) \mathrm{AlSi}_{3} \mathrm{O}_{8}$ & 558 & - & 406 & - & - \\
\hline & $\mathrm{CaAl}_{2} \mathrm{Si}_{2} \mathrm{O}_{8}$ & 35 & - & 20 & - & - \\
\hline & $\mathrm{Al}_{2} \mathrm{O}_{3}$ & 15 & - & 12 & - & - \\
\hline \multirow[t]{3}{*}{ Calcium } & Total & 278 & 648.1 & 106 & 208.9 & 439.2 \\
\hline & $\mathrm{CaSO}_{4}$ & 263 & - & 101 & - & - \\
\hline & $\mathrm{CaCO}_{3}$ & 15 & - & 5 & - & - \\
\hline Total & & & 6949.7 & & 2615.5 & 4334.2 \\
\hline
\end{tabular}


of mineral dust. The 'sulphur' class particles, assigned to vehicular exhausts, were of minor importance and were at background concentrations at all three sampling sites.

The detailed information on morphology and chemical composition of the particles obtained by CCSEM was used to quantify the railway induced particle concentrations of the railway lines. It has been shown that the 'iron' class particles contribute most to the railway related PM10 $\left(2.9 \mathrm{\mu g} \mathrm{m}^{-3}\right)$, followed by the particles of the 'aluminium' $\left(1.0 \mu \mathrm{g} \mathrm{m}^{-3}\right)$ and the 'calcium' $\left(0.4 \mu \mathrm{g} \mathrm{m}^{-3}\right)$ class. The particles of the 'silicon' and 'sulphur' class are of minor importance. Results from CCSEM analysis are in good agreement with gravimetric measurements of samples collected at the same sampling site in another study (Gehrig et al. 2007).

In the current study it was demonstrated that the automated analysis of small portions of filters by CCSEM combined with thorough data processing can produce results that are comparable with gravimetric methods. The results demonstrate that detailed single particle analysis not only provides comprehensive data of individual particles (morphology and chemistry) but can be used for a size, mass and chemistry resolved description of aerosols as well.

\section{References}

Aarnio, P., Yli-Tuomi, T., Kousa, A., Mäkelä, T., Hirsikko, A., Hämeri, K., Räisänen, M., Hillamo, R., Koskentalo, T. and Jantunen, M. (2005). The concentrations and composition of and exposure to fine particles (PM2.5) in the Helsinki subway system. Atmos. Environ. 39:5059-5066.

Adams, H. S., Nieuwenhuijsen, M. J. and Colvile, R. N. (2001). Determinants of fine particle (PM2.5) personal exposure levels in transport microenvironments, London, UK. Atmos. Environ. 35:4557-4566

Baron, P. A. and Willeke, K. (2001). Aerosol Measurements: Principals, Techniques, and Applications. John Wiley \& Sons, New York.

Birenzvige, A., Eversole, J., Seaver, M., Francesconi, S., Valdes, E. and Kulaga, H. (2003). Aerosol characteristics in a subway environment. Aerosol Science And Technology 37:210-220.

Buseck, P. R., Jacob, D. J., Posfai, M., Li, J. and Anderson, J. R. (2000). Minerals in the air: An environmental perspective. Int Geol. Rev. 42:577-593.

Chen, Y. Z., Shah, N., Huggins, F. E. and Huffman, G. P. (2005). Transmission electron microscopy investigation of ultrafine coal fly ash particles. Environ. Sci. Technol. 39:1144-1151.

Chillrud, S. N., Epstein, D., Ross, J. M., Sax, S. N., Pederson, D., Spengler, J. D. and Kinney, P. L. (2004). Elevated airborne exposures of teenagers to manganese, chromium, and iron from steel dust and New York City's subway system. Environ. Sci. Technol. 38:732-737

Gehrig, R., Hill, M., Lienemann, P., Zwicky, C. N., Bukowiecki, N., Weingartner, E., Baltensperger, U. and Buchmann, B. (2007) Railway traffic - a source of fine particles? Contribution of railway traffic to local PM10 concentrations in Switzerland. Atmos. Environ. 41:923-933.

Harrison, R. M. and Yin, J. X. (2000). Particulate matter in the atmosphere: which particle properties are important for its effects on health? Sci. Total Environ. 249:85-101.

Johansson, C. and Johansson, P. A. (2003). Particulate matter in the underground of Stockholm. Atmos. Environ. 37:3-9.

Katrinak, K. A., Anderson, J. R. and Buseck, P. R. (1995). Individual Particle Types In The Aerosol Of Phoenix, Arizona. Environ. Sci. Technol. 29:321-329.

Kupiainen, K. J., Tervahattu, H., Raisanen, M., Makela, T., Aurela, M. and Hillamo, R. (2005). Size and composition of airborne particles from pavement wear, tires, and traction sanding. Environ. Sci. Technol. 39:699-706.

Li, J., Anderson, J. R. and Buseck, P. R. (2003a). TEM study of aerosol particles from clean and polluted marine boundary layers over the North Atlantic. J. Geophys. Res.-Atmos. 108.

Li, J., Posfai, M., Hobbs, P. V. and Buseck, P. R. (2003b). Individual aerosol particles from biomass burning in southern Africa: 2 , Compositions and aging of inorganic particles. J. Geophys. Res.Atmos. 108.

Oberdorster, G. (1995). Lung Particle Overload - Implications for Occupational Exposures to Particles. Regul. Toxicol. Pharmacol. 21:123-135.

Oberdorster, G., Gelein, R. M., Ferin, J. and Weiss, B. (1995). Association of Particulate Air-Pollution and Acute Mortality Involvement of Ultrafine Particles. Inhal. Toxicol. 7:111-124.

Paoletti, L., Diociaiuti, M., De Berardis, B., Santucci, S., Lozzi, L. and Picozzi, P. (1999). Characterisation of aerosol individual particles in a controlled underground area. Atmos. Environ. 33:3603-3611.

Pfeifer, G. D., Harrison, R. M. and Lynam, D. R. (1999). Personal exposures to airborne metals in London taxi drivers and office workers in 1995 and 1996. Sci. Total Environ. 235:253-260.

Pope, C. A. (2000). Review: Epidemiological Basis for Particulate Air Pollution Health Standards. Aerosol Science and Technology 32:4-14

Posfai, M., Simonics, R., Li, J., Hobbs, P. V. and Buseck, P. R. (2003). Individual aerosol particles from biomass burning in southern Africa: 1. Compositions and size distributions of carbonaceous particles. J. Geophys. Res.-Atmos. 108.

Rosenbohm, E., Vogt, R., Scheer, V., Nielsen, O. J., Dreiseidler, A., Baumbach, G., Imhof, D., Baltensperger, U., Fuchs, J. and Jaeschke, W. (2005). Particulate size distributions and mass measured at a motorway during the BAB II campaign. Atmos. Environ. 39:5696-5709.

Sharan, M., Singh, M. P. and Yadav, A. K. (1996). Mathematical model for atmospheric dispersion in low winds with eddy diffusivities as linear functions of downwind distance. Atmos Environ. 30:1137-1145.

Sitzmann, B., Kendall, M., Watt, J. and Williams, I. (1999). Characterisation of airborne particles in London by computercontrolled scanning electron microscopy. Sci. Total Environ. 241:63-73.

VanBorm, W. A. and Adams, F. C. (1988). Cluster-Analysis Of Electron-Microprobe Analysis Data Of Individual Particles For Source Apportionment Of Air Particulate Matter. Atmos. Environ. 22:2297-2307.

VanMalderen, H., VanGrieken, R., Bufetov, N. V. and Koutzenogii, K. P. (1996a). Chemical characterization of individual aerosol particles in central Siberia. Environ. Sci. Technol. 30:312-321.

VanMalderen, H., VanGrieken, R., Khodzher, T., Obolkin, V. and Potemkin, V. (1996b). Composition of individual aerosol particles above Lake Baikal, Siberia. Atmos. Environ. 30:1453-1465.

Xhoffer, C., Bernard, P., VanGrieken, R. and Vanderauwera, L. (1991). Chemical Characterization And Source Apportionment Of Individual Aerosol-Particles Over The North-Sea And The English-Channel Using Multivariate Techniques. Environ. Sci. Technol. 25:1470-1478. 